\title{
An interesting case of a self-apposing stent implantation in an aneurysmatically dilated artery in acute myocardial infarction with high quality optical coherence tomography images ${ }^{2}$
}

\author{
Michał Węgiel ${ }^{\mathrm{a}, \mathrm{b}, *}$, Artur Dziewierz $^{\mathrm{b}}$, Łukasz Rzeszutko $^{\mathrm{b}}$, Dariusz Dudek ${ }^{\mathrm{a}, \mathrm{b}}$ \\ a Clinic of Interventional Cardiology, Jagiellonian University Medical College, Prądnicka 80 Street, 31-202 Kraków, Poland \\ b 2nd Department of Cardiology, University Hospital, Kopernika 17 Street, 31-501 Kraków, Poland
}

\section{A R T I C L E I N F O}

\section{Article history:}

Received 2 April 2017

Received in revised form 13 May 2017

Accepted 15 May 2017

Available online 16 May 2017

\begin{abstract}
A B S T R A C T
56-Year-old man with non-ST-segment elevation myocardial infarction. Coronary angiography showed aneurysmatic changes of the left circumflex artery with near occlusion of this vessel. We have decided to implant a Self-Apposing $®$ Coronary Stent Xposition S (Stentys SA, Paris, France). In optical coherence tomography a good stent apposition has been confirmed. A complete distal flow in the infarct-related artery was achieved. Implantation of DES in a large vessel, especially with aneurysmatic dilatation is limited due to difficulties in choosing a proper stent size. Undersizing may cause stent malapposition which carries an increased risk of late and very late stent thrombosis. Oversizing may lead to dissection or even vessel perforation. In presented case choosing a proper stent size was not so easy because of aneurysmatic changes of the artery. The vessel diameter in the aneurysm area was about $6 \mathrm{~mm}$. Regular DES are commercially available in maximal sizes up to $4.5-5.0 \mathrm{~mm}$. In this case we have chosen the largest Stentys stent size available $(3.5-4.5 \times 27 \mathrm{~mm})$ which is designed to target vessels of diameter between 3.5 and $6.0 \mathrm{~mm}$. Self-apposing stents present useful features which might have advantages over conventional drug-eluting stents in specific angiographic situations.

(C) 2016 The Society of Cardiovascular Academy. Production and hosting by Elsevier B.V. This is an open access article under the CC BY-NC-ND license (http://creativecommons.org/licenses/by-nc-nd/4.0/).
\end{abstract}

\section{Introduction}

Implantation of a new-generation drug-eluting stent (DES) is a preferred method of reperfusion in patients with acute myocardial infarction (MI) in most angiographic situations. ${ }^{1,2}$ However, these devices also have some limitations. They are commercially available in maximal sizes up to $4.5-5.0 \mathrm{~mm}$. Implantation of DES in a large vessel, especially with aneurysmatic dilatation is limited due to difficulties in choosing a proper stent size. Undersizing may cause stent malapposition which carries an increased risk of late and very late stent thrombosis. On the other hand, oversizing may lead to dissection or even vessel perforation. $^{1,3}$

\footnotetext{
is Peer review under responsibility of The Society of Cardiovascular Academy.

* Corresponding author at: Clinic of Interventional Cardiology, Jagiellonian University Medical College, Prądnicka 80 Street, 31-202 Kraków, Poland.

E-mail addresses: michal.wegiel@uj.edu.pl (M. Węgiel), lrzeszutko@cathlab.krakow.pl (Ł Rzeszutko), mcdudek@cyfronet.pl (D. Dudek).
}

\section{Case report}

A 56-year-old Caucasian man was transferred to our department because of non-ST-segment elevation MI. On admission the patient was clinically stable. The ECG showed sinus rhythm, 50 beats per minute, negative T waves in III, aVF. Transthoracic echocardiography revealed hypokinesis of the middle and apical segment of the lateral wall with left ventricular ejection fraction of $60 \%$. The patient was treated with a loading dose of acetylsalicylic acid and unfractionated heparin and was transferred to the cathlab for a coronary angiogram. Coronary angiography performed through the radial access showed aneurysmatic changes of the left circumflex artery with near occlusion of this vessel (90\% stenosis by visual assessment) (Fig.1). A loading dose of ticagrelor has been administered and an immediate PCI of the infarct-related artery with guiding catheter Launcher 6FEBU 4.0, and BMW guidewire was performed. Pre-dilatation with balloon-catheter Maverick 3.5 $\times 15 \mathrm{~mm}$ up to $8 \mathrm{~atm}$. Due to ectatic dilatation of the artery we have decided to implant a Self-Apposing $®$ Coronary Stent Xposition S (Stentys SA, Paris, France). Post-dilatation was performed with $4.5 \times 15 \mathrm{~mm}$ balloon catheter Maverick XL inflated to 6-8 atm. In optical coherence tomography (OCT) a good stent apposition has been confirmed with a few not adhering struts. The maximal distance between stent struts and the vessel wall was $0.5 \mathrm{~mm}$ (Figs. 1 and 2). A complete distal flow 


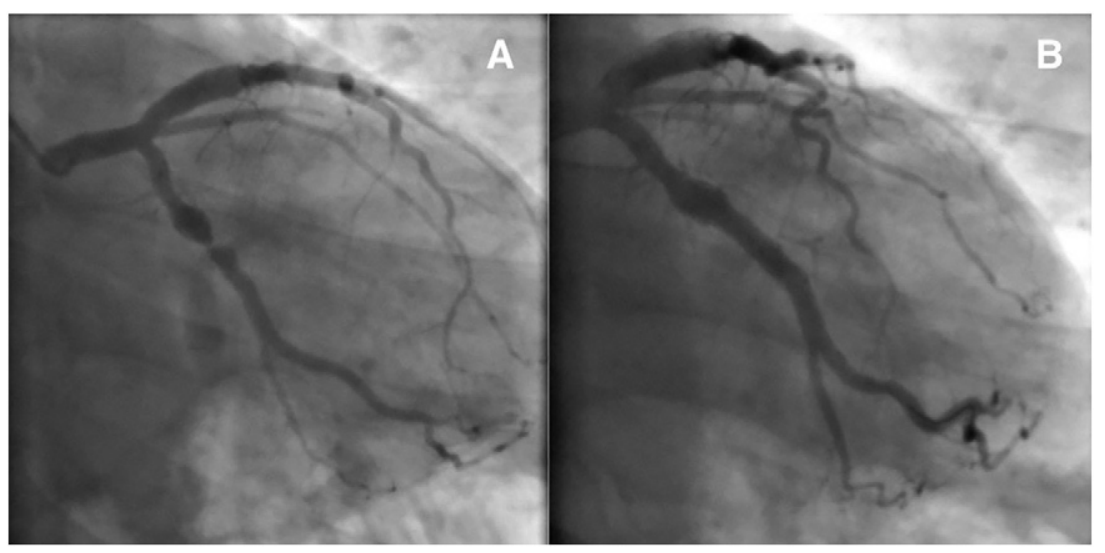

Fig. 1. Fluoroscopy image of the left coronary artery. A - left circumflex artery before the procedure; B - left circumflex artery after the procedure.

in the infarct-related artery was achieved. After four days of hospitalization the patient was discharged home in a good general condition with a recommendation for the use of dual antiplatelet therapy (acetylsalicylic acid and ticagrelor) for 12 months.

\section{Discussion}

Recently, Stentys company has presented a sirolimus-eluting version of Stentys stent (Xposistion S) with a new balloon delivery system aimed to facilitate stent positioning. The stent is now mounted on a semi-compliant balloon and is restrained by a splittable sheath. The balloon is inflated to relatively low pressures, only in order to split the sheath and release the stent. After deflation the balloon and sheath are withdrawn leaving the stent apposed to the vessel wall. This overcomes a forward jump complication of the device know from the previous trigger delivery system. ${ }^{4-6}$ The latest version of Stentys Xposition $S$ presents radio-opaque stent end markers to improve precise placement of the device. Self-apposing stents are particularly effective in angiographic situations where precise sizing is difficult. ${ }^{1}$ In presented case choosing a proper stent size was not so easy because of aneurysmatic changes of the artery. The vessel diameter in the aneurysm area was about $6 \mathrm{~mm}$ (Figs. 1 and 2). Regular DES are commercially available in maximal sizes up to $4.5-5.0 \mathrm{~mm}$. In this case we have chosen the largest Stentys stent size available $(3.5-4.5 \times 27 \mathrm{~mm})$ which is designed to target vessels of diameter between 3.5 and $6.0 \mathrm{~mm}$ (Fig. 2).

The efficacy and safety of Stentys Self-Apposing stent in ST-segment elevation MI patients has been confirmed previously. No malapposed

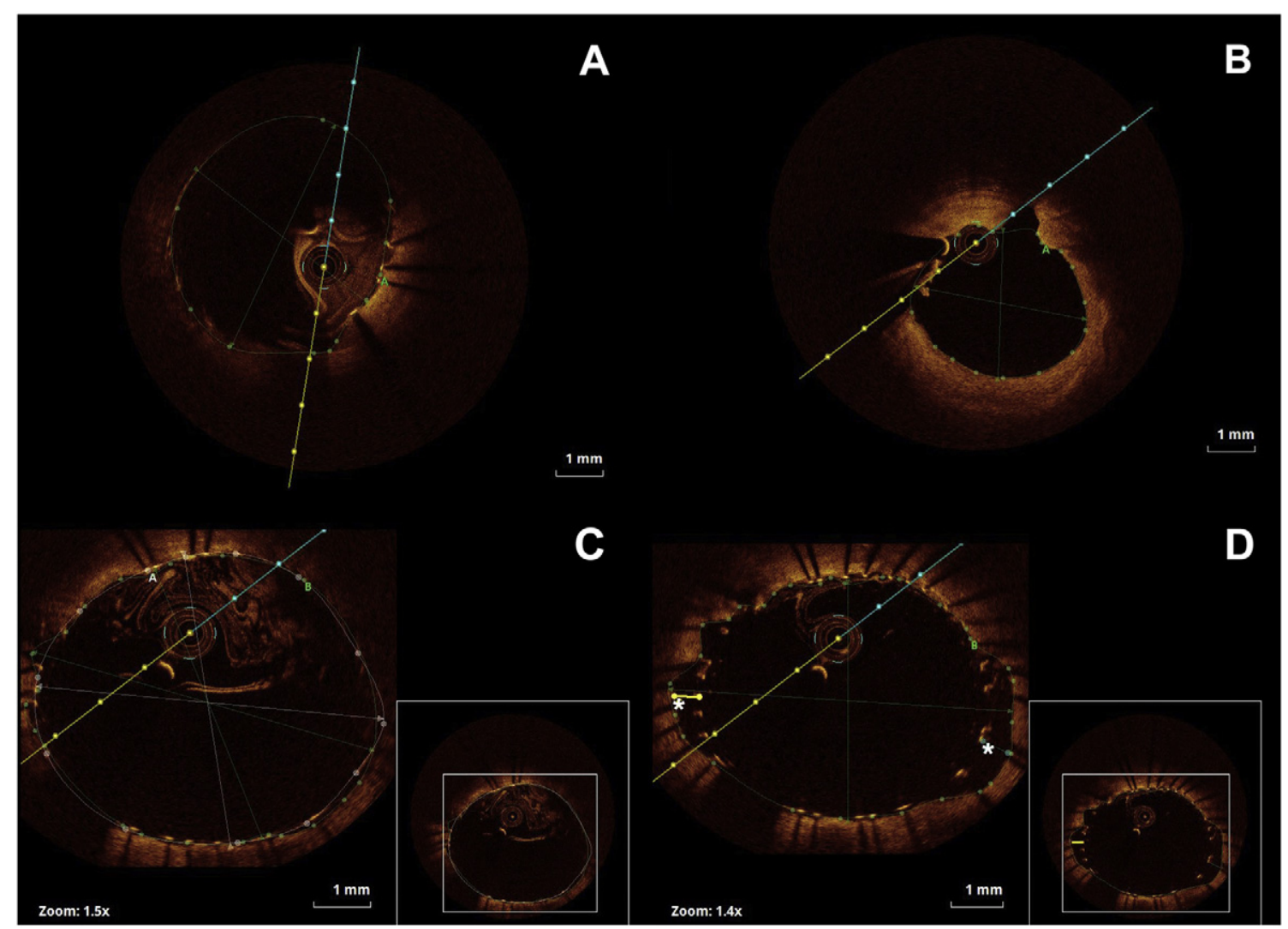

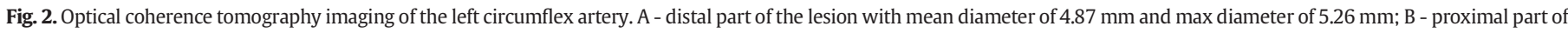

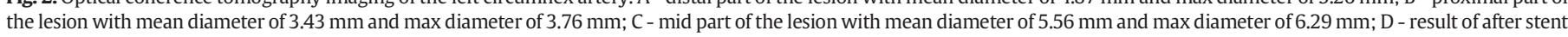
implantation without complete stent apposition $-0.5 \mathrm{~mm}$ (asterisk). 
stent struts at 6 months, and lower rate of acute stent malapposition (at 3 days) as compared to balloon-expandable stents was reported. ${ }^{7-9}$ In our case we performed post-dilatation after stent implantation, which is currently recommended to decrease the risk of late in-stent thrombosis. $^{10}$

Self-apposing stents present useful features which might have advantages over conventional DES in specific angiographic situations. Thus, self-apposing stents could become a new therapeutic option for selected patients.

\section{Conflict of interest}

The authors report no relationships that could be construed as a conflict of interest.

\section{References}

1. Dziewierz A, Dudek D. Choosing the right stent for patients with ST-segment elevation myocardial infarction: the evidence-based approach. Minerva Cardioangiol 2016 Jun;64:265-283.

2. Stefanadis CI. Stents for coronary artery disease: from covered to drug-eluting to bioabsorbable. Hellenic J Cardiol 2012 Jan-Feb;53:89-90.
3. Silenzi S, Grossi P, Mariani L, Aimi A, Marchese P, Moretti L. A real world single centre experience using the STENTYS self-expanding coronary stent. Int J Cardiol $2016 \mathrm{Apr}$ 15;209:57-59.

4. Pyxaras SA, Schmitz T, Naber CK. The STENTYS Self-Apposing ${ }^{\circledR}$ stent. EuroIntervention 2015;11:V147-V148.

5. Yew KL. Early experience of transradial multivessel percutaneous coronary intervention with new generation STENTYS sirolimus eluting self-apposing stents for ectatic coronary arteries. Int J Cardiol 2015 Apr 15;185:155-156.

6. Yew KL. Optimization of Stentys Xposition S self-apposing sirolimus eluting stent expansion and apposition with coronary lesion debulking strategy utilizing cutting balloon. Int J Cardiol 2016 Jan 15;203:1007-1008.

7. Amoroso G, van Geuns RJ, Spaulding C, Manzo-Silberman S, Hauptmann KE, Spaargaren R. Assessment of the safety and performance of the STENTYS self-expanding coronary stent in acute myocardial infarction: results from the APPOSITION I study. EuroIntervention 2011 Aug:7:428-436.

8. van Geuns RJ, Tamburino C, Fajadet J, et al. Self-expanding versus balloon-expandable stents in acute myocardial infarction: results from the APPOSITION II study: self-expanding stents in ST-segment elevation myocardial infarction. JACC CardiovasC Interv 2012 Dec:5:1209-1219.

9. van Geuns RJ, Yetgin T, La Manna A, et al. STENTYS Self-Apposing ${ }^{\circledR}$ sirolimus-eluting stent in ST-segment elevation myocardial infarction: results from the randomised APPOSITION IV trial. EuroIntervention 2016 Feb 12;11:e1267-e1274.

10. Koch KT, Grundeken MJ, Vos NS, IJsselmuiden AJ, van Geuns RJ, Wessely R. One-year clinical outcomes of the STENTYS Self-Apposing coronary stent in patients presenting with ST-segment elevation myocardial infarction: results from APPOSITION III registry. EuroIntervention 2015 Jul;11:264-271. 